\title{
Reproductive characterization of the female Mexican turkey (Meleagris gallopavo L.)
}

\author{
López-Pérez, Elvia ${ }^{1}$; Gallegos-Sánchez, Jaime ${ }^{2}$; Pró-Martínez, Arturo ${ }^{2 *}$; \\ Cuca-García, Juan Manuel $^{2}$; Herrera-Barragán, Juan Antonio ${ }^{3}$ \\ 1 Universidad Autónoma Chapingo. Departamento de Zootecnia. Carretera México-Texcoco km 38.5 \\ Chapingo, Texcoco, Estado de México, México. C. P. 56230. \\ 2 Colegio de Postgraduados Campus Montecillo. Carretera México-Texcoco km 36.5, Montecillo, Texcoco, \\ Estado de México. C. P. 56230. \\ 3 Universidad Autónoma Metropolitana Xochimilco. Calzada del Hueso 1100, Villa Quietud, Coyoacán, \\ CDMX, México. C. P. 04960. \\ * Corresponding author: aproma@colpos.mx
}

Citation: López-Pérez, E., GallegosSánchez, J., Pró-Martínez, A., CucaGarcía, J. M., \& Herrera-Barragán, J. A (2021). Reproductive characterization of the female Mexican turkey (Meleagris gallopavo L.). Agro Productividad. https:// doi.org/10.32854/agrop.v14i8.2064

Editor in Chief: Dr. Jorge Cadena Iñiguez

Received: February, 2021.

Accepted: August, 2021.

Estimated publication date: September, 2021

This work is licensed under a Creative Commons Attribution-NonCommercial 4.0 International license.

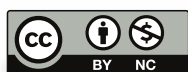

\section{ABSTRACT}

Objective: To describe the anatomy, morphology, physiology, and reproductive characteristics of female turkeys.

Design/methodology/approach: An analysis of the practical experiences of 10 years with Mexican native turkeys was conducted and complemented with scientific literature. We focused on reproductive aspects, anatomy, physiology and assisted reproduction.

Results: Information on the breeding of Mexican native turkeys is scarce, few families in rural areas are dedicated to raising this poultry. Therefore, empirical knowledge on their management is being lost. The female turkey begins oviposition at 6 months of age with a body weight between 2 and $4 \mathrm{~kg}$. The structures that make up their reproductive system are the ovary, developing follicles, left oviduct, and cloaca. The reproductive activity is initiated by photo receptors located in the retina and pineal gland, triggering follicle stimulating and luteinizing hormones release. Egg formation lasts from 24 to 26 hours. During the first year, females lay between 36 to 54 eggs in clutches of 12 to 18 eggs and in the second year from 30 to 45 eggs. Chloequez is prolactin induced. As for assisted reproduction, artificial insemination techniques in female turkeys are uncommon.

Limitations on study/implications: Few rural families raise turkeys and since they lack economic resources, reproductive strategies are not used to improve their production.

Findings/conclusions: The anatomical, morphological, physiological and reproductive characteristics of the native female turkeys from Mexico were documented. In native turkeys, artificial insemination techniques are not of common use, but their implementation may be adequate to conserve genetic material from animals with outstanding characteristics.

Key words: native bird; egg; conservation; assisted reproduction.

\section{INTRODUCTION}

The native Mexican turkey (Meleagris gallopavo Linn) is considered one of the few native Mexican species used for productive purposes. It is raised by families in rural and peri-urban areas to supply animal protein. Due to its toughness, it survives precarious 
feeding conditions, climate, and management. At the same time, proposals have been made to implement nutritional and reproductive technologies to improve production and develop meleagriculture at rural level as a family business. However, little is known about the reproductive physiology of the hens (female turkeys), so this research focuses on characterizing the productive parameters related to this topic, gathered through several years of research in the native turkey production module of at the Universidad Autónoma Chapingo, to improve zootechnical and productive management, as well as to contribute to their conservation and their use as a common consumption species, not only for religious festivities.

\section{DESGRIPTION}

The female is of slender build, their weight is variable depending on its nutritional and physiological state, in research developed for several years by the authors of this document at the Universidad Autónoma Chapingo, weights have been recorded ranging from 2 to 4 kilograms in turkey hens kept in a grazing-confinement. Their lowest weights correspond to females in broodiness state. The plumage coloration varies (Figure 1), it ranges from grayish to black tones, finding specimens with white and even brown plumage, all in iridescent metallic tones, although the color of the hens is less bright than that of the males.

The color of the neck and head has a blue-grayish hue covered with plumage-colored feathers. Some fleshy red protuberances fall from the front and sides of the neck, called caruncles or corals, and a fleshy flap of pink to red skin called wattle attaches to the throat and neck. In front of the beak hangs a small fleshy appendage which is called the snood (Figure 2). Occasionally, some females grow a small appendage with coarse hairs in front of the chest called a beard or scabbard. The legs have a rudimentary rounded spur.

\section{REPRODUCTIVE MORPHOLOGY AND PHYSIOLOGY}

The structures of the reproductive apparatus of the turkey hens are the ovary, developing follicles, left oviduct, uterus and cloaca (Figure 3).

Ovary. located on the left side of the ventral coelomic cavity of the turkey hens. It presents an internal medulla and external cortex, which contains the follicles attached to the ovary through a pedicel or stroma (Peralta, 2017). Each follicle or yolk reaches 40 to

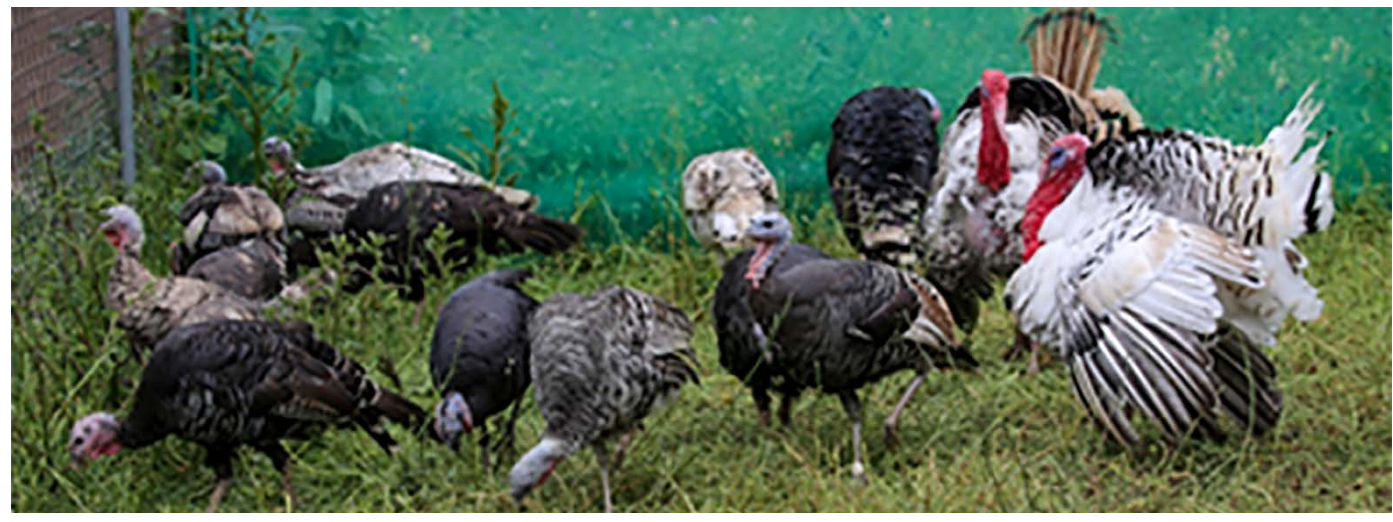

Figure 1. Some variations in native turkey plumage coloration (Meleagris gallopavo). 


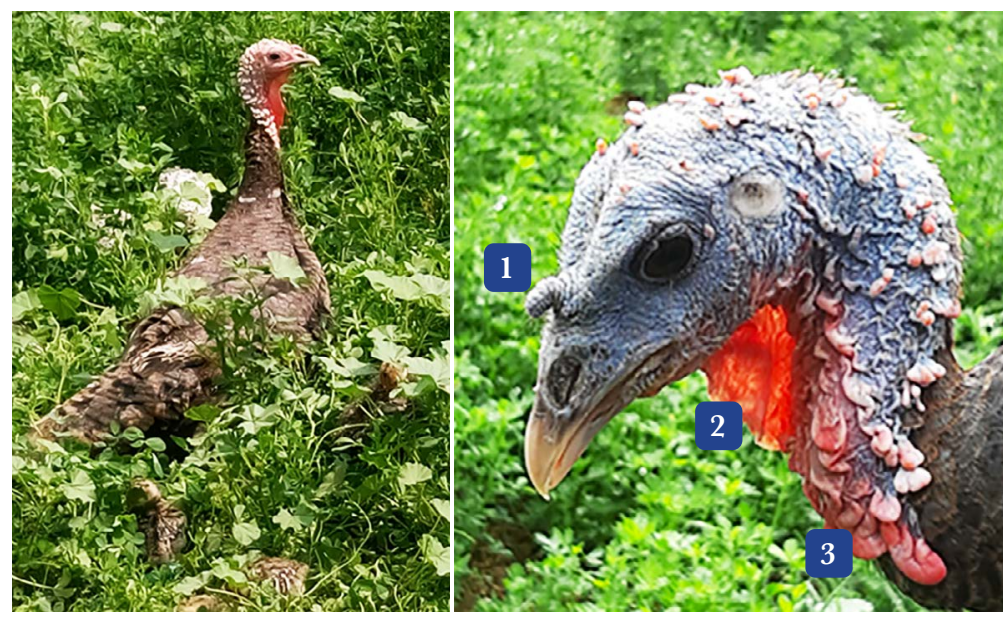

Figure 2. Facial characteristics of native turkey hens: $\operatorname{snood}(1)$, wattle(2) and caruncles (3).

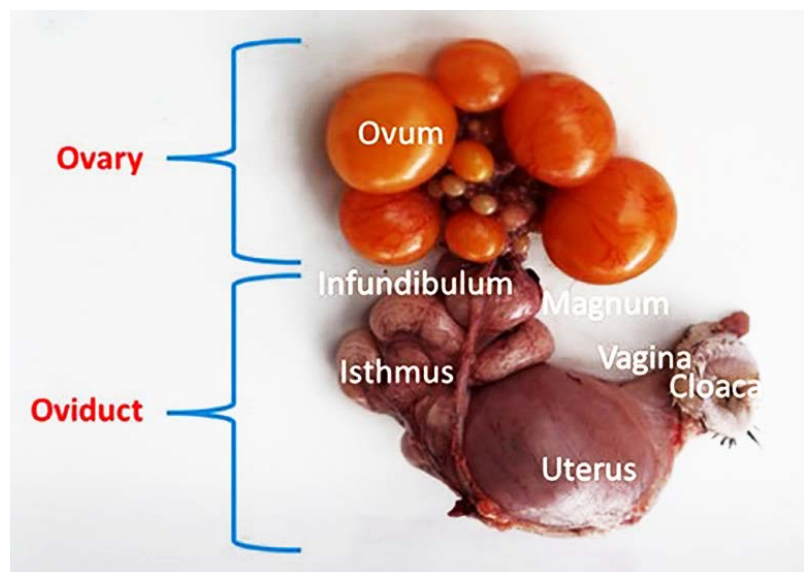

Figure 3. Structures of the reproductive apparatus of native Mexican turkey.

$42 \mathrm{~mm}$ in size before ovulation. It resembles a grapes cluster made up of a group of more than 100 visible follicles, and more than 10,000 of microscopic size. However, of these only 120 to 180 reach maturity and are ovulated, considering a productive life of 3 years. When turkey hens reach sexual maturity (224 days) they begin to ovulate, which seems to be influenced by the time of birth and nutritional status. Overall, turkey hens begin laying at 6 months of age; however, others begin laying at 8- or 9-months age. Most turkeys start laying when they reach $3 \mathrm{~kg}$ in weight. The egg yolk, or vitellus, is formed in the ovary (Figure 4). Once it reaches a size of more than $30 \mathrm{~mm}$ with the oocyte, it is released from the follicle by breaking along a line called the stigma, which is the least irrigated and falls into the infundibulum.

Oviduct. The oviduct is a pink tube that begins near the ovary and reaches the cloaca (Figure 5). Five segments are identified: 1) Infundibulum. It is the first part of the oviduct, approximately $11 \mathrm{~cm}$ long, has a funnel shape and folds in the internal mucosa, its function is to receive the yolk with the oocyte and here is where fertilization occurs, through contractions the egg information takes 15 to 30 minutes to pass through this region. 2) Magnum. It presents folds and its walls are elastic with many secretory glands, here most 

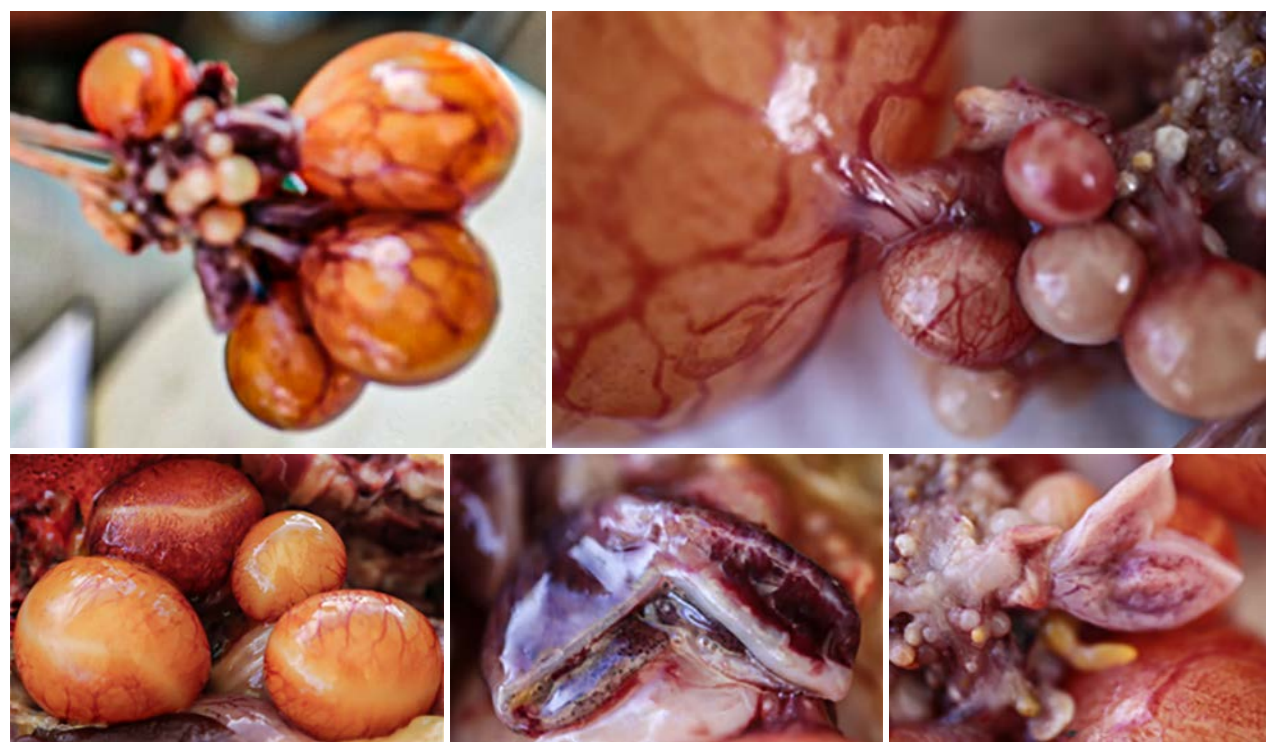

Figure 4. Ovary of turkey hens showing mature and immature yolks. Note the stigma, ruptured follicles and regressing follicles as mature yolks are released.
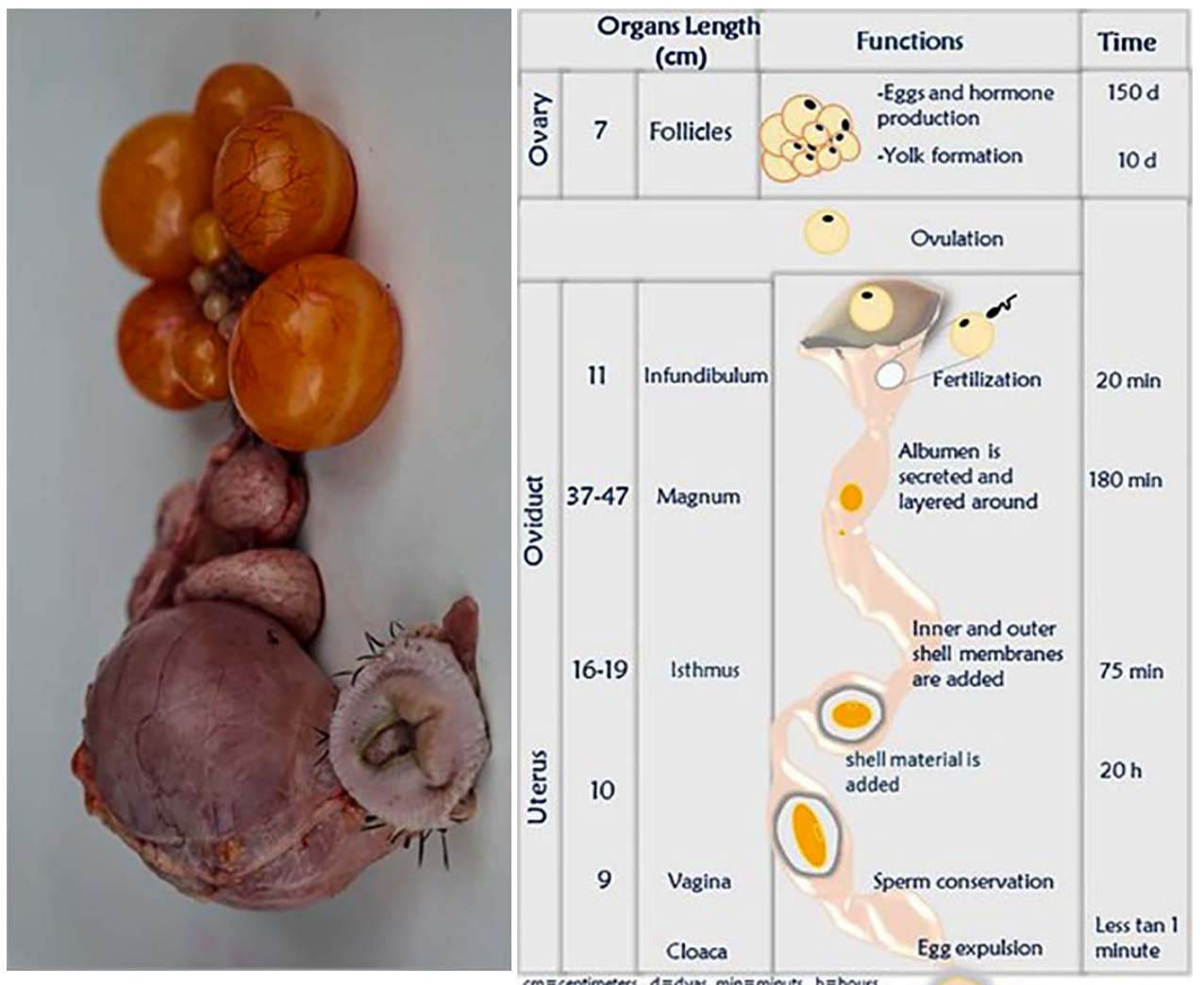

$c m=$ centimeters, $d=d y$ os. min $=$ minuth, hahours

Egg

Figure 5. Reproductive apparatus of turkey hens, measurements, function, and time of egg formation. 
of the albumin protein is produced (Ricaurte, 2006; Cuca et al., 2009). The yolk passes this region in 2 to 3 hours, which is the largest in the oviduct (37 to $47 \mathrm{~cm}$ in length). 3) Isthmus. The most evident characteristic to distinguish this part from the others is the reduction of its diameter, there are mucosal folds, although less accentuated. In this part the testaceous membranes (internal and external) are formed and the formation of the eggshell begins, adding the minimum amount of water, so when the forming egg leaves the isthmus, it has a wrinkled appearance, the time it takes to pass through this region is $1 \frac{1 / 4}{4}$ hour and measures 16 to $19 \mathrm{~cm}$ in length. 4) Uterus. This portion of the oviduct resembles a bag with very thick muscular walls, in this region the eggshell and chalazae are formed, water and salts are added to the albumin through the shell membranes by osmosis. This is the part in which the egg remains for the longest time, approximately 20 hours. The uterus is approximately $10 \mathrm{~cm}$ long. 5) Vagina. It is approximately $9 \mathrm{~cm}$ long. It is a narrow, muscular tube extending from the uterus to the cloaca, through which the egg is expelled. In this part, the egg rotates to exit through the sharpest pole by the cloaca, also in this region the cuticle membrane that surrounds the eggshell is formed, which is constituted by lysozyme and works as a barrier against bacteria (Ricaurte, 2006); the tubular glands are in the utero-vaginal junction in which the sperm is stored, when an egg is ovoposited, part of the sperm is conducted towards the infundibulum to fertilize another oocyte. According to Abad et al. (2003), one theory is that the sperm release from the sperm nests occurs when peristaltic contractions occur during oviposition. However, Sauveur and Reviers (1992) indicate that the infundibulum dilates with the arrival of the yolk, and this produces a release and migration of spermatozoa from the tubular glands into the infundibulum where fertilization occurs.

Cloaca. It is the final segment of the reproductive tract and is where the digestive and urinary systems end, and through which the egg is expelled. Studies by Bakst and Akufo (2008) showed that once semen is deposited in the cloaca of the female during copulation, it enters the urodeal tubular glands and is gradually transferred to the vagina and from there it is transported to the sperm storage tubules.

Oogenesis and follicular growth. Since turkey hens oviposit one egg per day or every third day depending on the nutritional or physiological state, egg formation is considered to have a duration of 24 to 26 hours for the time that the egg is in formation in the different parts of the oviduct (Cuca et al., 2009). Oogenesis is the process during which a series of nuclear and cytoplasmic changes occur in the ovogonia, giving rise to primary oocytes (Peralta and Miazzo, 2002).

Photoperiod and reproductive activation. The reproductive activity of poultry, including native turkey hens, is initiated by photoreceptors located in the retina and pineal gland. Birds perceive seasonal changes (darkness) which are translated into hormonal signals mediated by melatonin (N-acetyl-5-methoxytrytrytryptamine), a compound synthesized in the pineal gland (Illnait-Ferrer, 2012). According to Robinson and Renema (1999) light energy passes through the skull and stimulates photoreceptors in the hypothalamus. 11 to 12 hours of light per day are necessary for the onset of the bird's reproductive activity, this light energy is converted into nerve impulses in the hypothalamus, which triggers a hormonal cascade with the release of follicle stimulating hormones (FSH) and luteinizing 
hormones (LH) from the anterior hypophysis which aims at the growth of follicles, estrogen production and ovulation. (Figure 6).

FSH stimulates follicles growth. Growing follicles are the main source of estrogen and as they develop, they tend produce progesterone. LH regulates ovarian development, sex steroid secretion and ovulation (Peralta and Miazzo, 2002). The ovary secretes steroids: estrogens, androgens and progesterone which exert a negative feedback effect on LH release. Estrogens are synthesized in the interstitial cells of the follicular thecae (Peralta and Miazzo, 2002) and their functions are: a) oviduct growth and regulation, b) participate in proteins synthesis and lipids for the yolk, c) participate in the transport of lipoproteins and calcium, d) participate in the synthesis of the egg white proteins, e) participate in the formation of medullary bone and calcium phosphate retention, f) induce behavior during oviposition, g) regulate the appearance of secondary sexual characteristics, and h) induce the separation of the pelvic bones to allow the egg to be oviposited. Progesterone is secreted by the granulosa cells of the pre-ovulatory and post-ovulatory follicle, although to a lesser extent from post-ovulation. Progesterone functions are related to, a) the oviduct growth, b) the synthesis of some albumen proteins, c) the ovulation control and oviposition rhythms, d) the release of Luteinizing Hormone Releasing Hormone (LHRH) which exerts control on uterine contractions prior to oviposition and on laying behavior. There is positive feedback between progesterone and $\mathrm{LH}$, which triggers a $\mathrm{LH}$ surge, responsible for producing ovulation (lmai, 1973).

In broody turkey hens, the pituitary gland is responsible for the secretion of prolactin, which maintains broodiness (Scanes, 1986). It should be noted that turkey hens are exceptionally sensitive to the effects of the photoperiod, so inducing broodiness by holding the birds in a "nest" space with low light effectively induces this behavior, which is also achieved by the presence of hatching eggs.

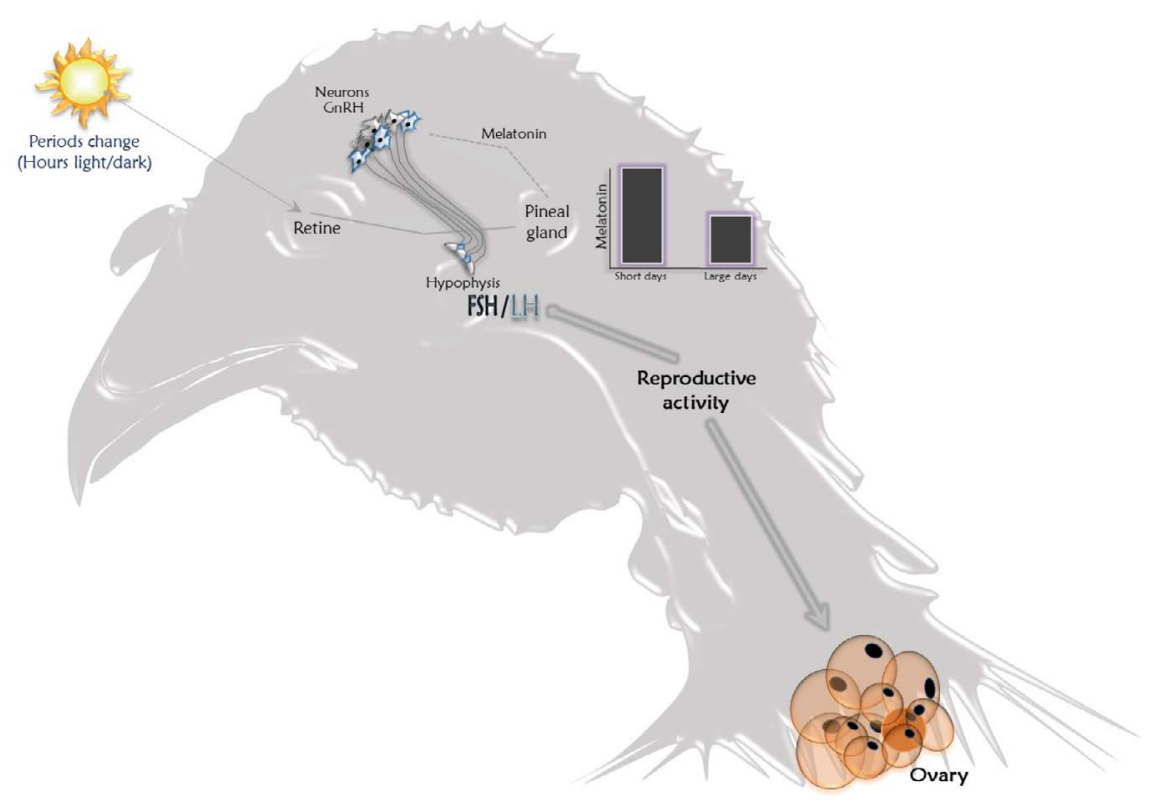

Figure 6. Effect of light and activation of reproductive physiology. 
Posture. In an experimental study by the authors in turkeys at the experimental farm of the Universidad Autónoma Chapingo, with a corn-soybean paste diet, it was recorded that turkeys start laying when they reach an average weight of $3 \mathrm{~kg}$. According to surveys $(n=20)$ conducted in field in communities form Puebla and Tlaxcala states, the results indicated that, during the first year, females oviposit 36 to 54 eggs in 12 to 18 eggs clutches and in the second year, 30 to 45 eggs. The laying season mainly occurs during spring and fall, although some extend the laying period until winter (Figure 7).

The egg. Turkey eggs (Figure 8) weigh between 70 and $95 \mathrm{~g}$, they have a $6.8 \pm 0.16 \mathrm{~cm}$ polar diameter and equatorial diameter of $5.3 \pm .014 \mathrm{~cm}$. Egg weight, in young females, is lower than that of mature females that have more than one laying cycle. Likewise, egg weight will depend on the nutritional status of turkey hens, and in some backyard birds whose diet is based on native forage plants (grazing), insects and larvae, weights vary from 62 to $85 \mathrm{~g}$. The color of turkey eggs goes from creamy white to light beige with darker color spots or dots (brown to reddish).

Eggs should be collected at least twice a day or more, to avoiding soiling or breakage by the birds. They should be kept in a cool place with their pointy side facing down. Hatching eggs should not be stored for more than 7 days after laying, as it has been found that eggs stored longer than this decreases their hatchability. If possible, dirty eggs with excrement

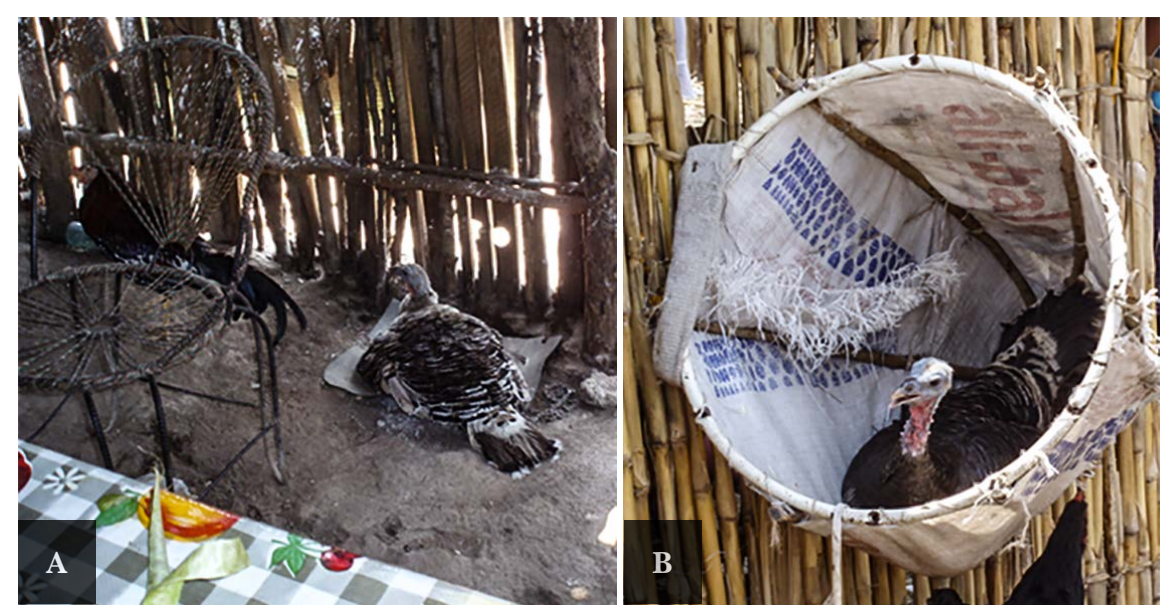

Figure 7. Turkey hens ovipositing in a house kitchen (7A) or in baskets of sticks and sacks (7B) in rural communities of Guerrero.
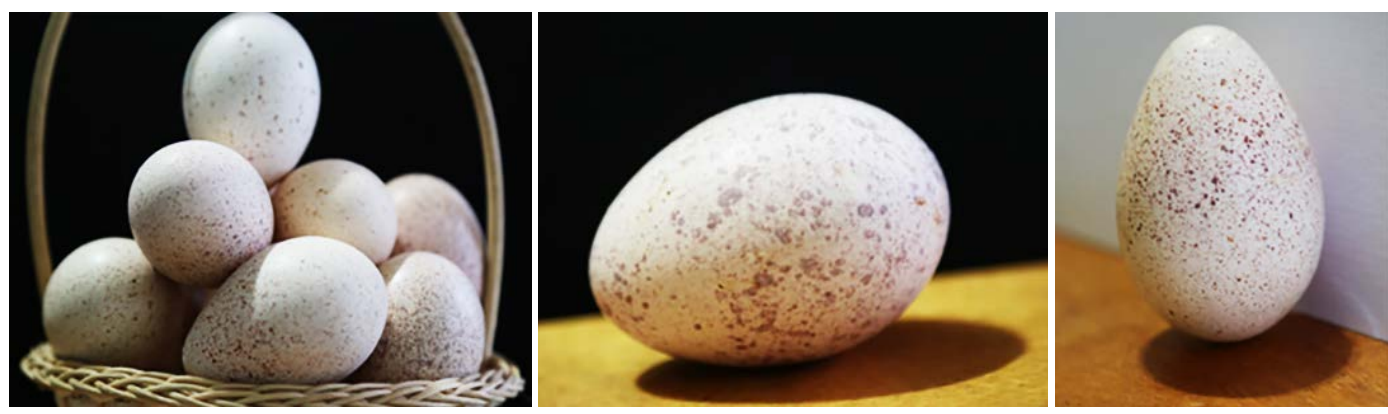

Figure 8. Turkey eggs, with characteristic spots. 
should be removed because they could transmit pathogens that could infect them during incubation. To prevent eggs from being broken or soiled, a bed of straw or any other material should be placed inside the nest or pen where the animals are kept.

Broodiness. This is a behavior derived from hormonal action, understood as the instinct for egg incubation, which lasts from 28 to 30 days and consists of stopping ovulation (oviposition) after having laid 12 to 18 eggs, then, the bird's behavior changes and tends to incubate the eggs (Figure 9).

The turkey hens remain most time in the nest and come out only for eating and drinking water, although on rare occasions, they do not leave the nest at all, which is why it is important to place food and water nearby. During this reproductive state, the turkey hens resist moving from the nest when their relocation is attempted; they emit different sounds than usual. The immobility reflex for mating and the nesting reflex are induced by increased steroid hormones. The nesting behavior is highly heritable and induced by estrogens secretion, especially progesterone, a hormone produced by the larger follicles that are close to ovulation. Turkey hens can maintain broodiness if the hatching eggs do not hatch or if the poults are removed at hatching. This fact has been used by some people who force them to incubate more than once in a continuous way, that is, the turkey hen incubates the first time, the hatchlings hatch and are removed, to develop in with artificial heat (Figure 10) and then another group of eggs is placed. A second flock is born, the hatchlings are then again removed, and more eggs are placed for a third time, which again, hatch and this time, when hatched, they are left, and the turkey hen begins a rearing period.

An important factor that stimulates this behavior is tactile contact with other eggs, secreting prolactin which maintains broodiness (Rodriguez, 2017). Some measures to remove the female from this state are: (a) remove the turkey hens from the nest and place them in cages with intense 24 hours a day light, this stress causes a decrease in prolactin levels in blood, which inhibits nesting; (b) newborn chicks are placed in the nest, their sounds indicates their birth, which is a signal to take care of them and leave the nest and dedicate herself to raising the turkey poults; (c) they are kept in cages for several weeks (Juárez and Gutiérrez, 2009); d) in rural communities, it is reported that turkeys are tied to an object such as a piece of animal skin or some other bulky object to their legs; then, due to the constant stress caused by having the object tied to its leg, the turkey concludes the broodiness in approximately one week. Prolactin secretion by the anterior pituitary is
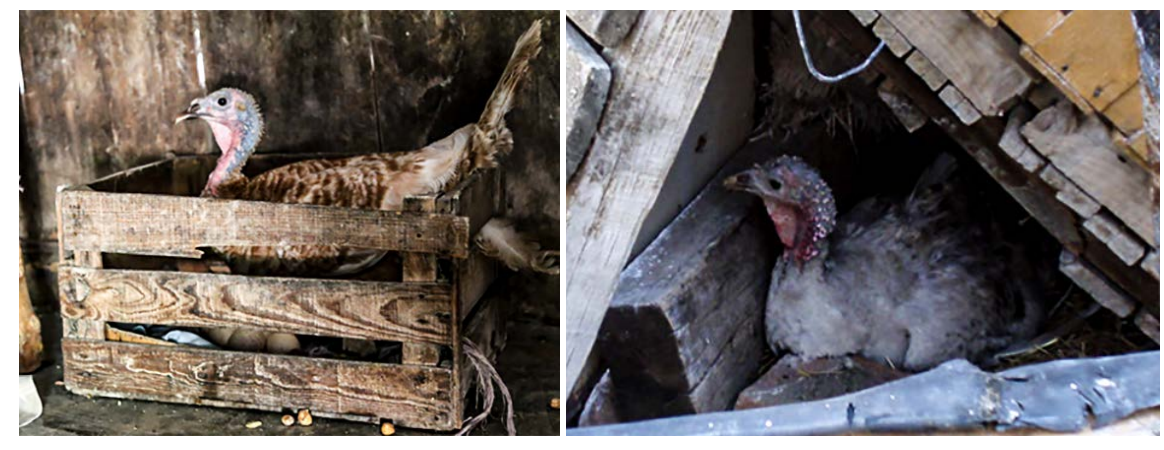

Figure 9. Turkey hens with clutches incubating in improvised rustic nests. 


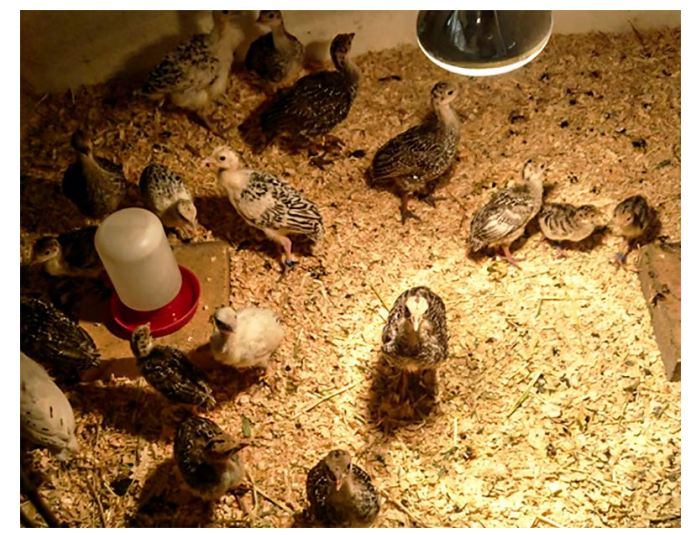

Figure 10. Rearing chicks with artificial heat.

controlled by prolactin-releasing hormone produced in the hypothalamus. High prolactin levels are accompanied by a reduction in luteinizing hormone responsible for ovarian involution and, in turn, a decrease in estrogen and progesterone levels. Likewise, the environment plays a fundamental role in the broodiness onset; turkeys seek an isolated, dark, warm area to serve as a nest, ideally with a present egg (Figure 10), therefore, if it is not desired that the turkey hens start brooding earlier than planned, the nests should be closed during the night.

Chicks rearing. When the turkey hen dedicates herself entirely to the care of the poults, after one to two months, the brooding cycle ends. However, this results in a reduction in egg production. During the year, the turkey hens can have three short production cycles or clutches laid after each cycle. For incubation, it is necessary to provide the brooding female with an appropriate nest, space, and depth so that the laying female has ample space to turn the eggs, change position and be comfortable during this period. After 28 to 30 days of hatching, the poults are born (Figure 11) with a weight of 60 to $75 \mathrm{~g}$, who must learn to eat on their own, because the mother does not feed them as often or attract them to eat with calls. Because of this in rural communities they are fed in the beak. Another way for the poults to learn to eat on their own is by laying chicken eggs to hatch chicks, and since they are very attracted to what surrounds them, they easily learn to eat, and the poults also learn to eat by observing the chicks.

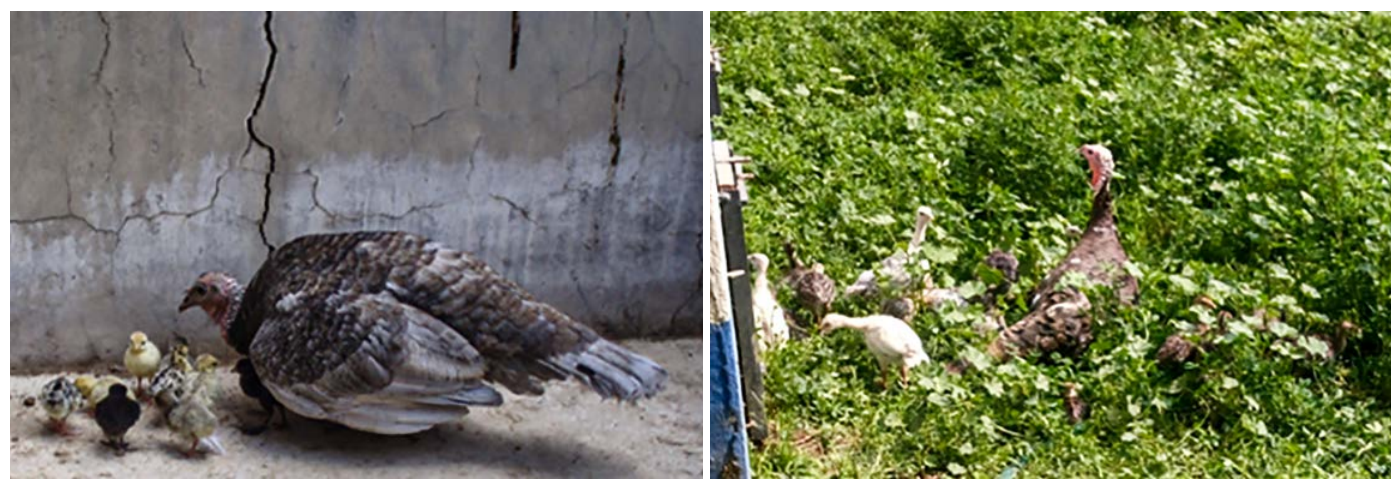

Figure 11. Turkey hens with newly hatched poults coming out of the nest. 
Molt. During this period, which occurs in late summer and early autumn, turkeys stop laying, drop their feathers, and undergo a series of physiological-hormonal changes that prepare them to begin another laying cycle. The molt can be total when they renew all or partial body feathers, limited to the feathers of certain areas. Moulting normally takes place from September to October, although early (July-August) and late (DecemberJanuary) molts have been recorded. In the case of males, partial molts have also been observed (Cuca et al., 2016).

\section{ASSISTED REPRODUGTION METHODS}

\section{Artificial insemination}

In turkey hens, unlike commercial turkeys, it is not common to use the artificial insemination (AI) techniques; however, using these techniques can be adequately conserve genetic material from native turkey animals with outstanding characteristics.

Technique. Ideally, the technique should be performed by two people to facilitate the work (the collector-inseminator and an assistant). The assistant places the turkeys on a board or colt in front of the inseminator or can also hold the turkey by its legs with special tongs, then the inseminator presses the turkey's abdomen with one hand until a slight evagination is provoked while inseminating with the other hand. Just before injecting the semen and with the already inserted straw (2-3 cm from the vagina), pressure on the abdomen should be released so that the semen is not expelled from the vagina (Abad et al., 2003).

Semen deposition. It is recommended that the semen be deposited in the middle of the vagina to avoid damage to the utero-vaginal junction and to prevent the sperm from being expelled, although insemination in the uterus or magnum has higher fertilization rates (Ricaurte, 2006).

Insemination timing. For convenience, it is recommended that AI be performed in the afternoon, when most of the eggs have been laid to prevent the shell egg from dragging the sperm out of the vagina, and the minimum time between oviposition and insemination should be 4 to 6 hours (Abad et al., 2003).

Insemination intervals. It is necessary to consider that turkeys should be inseminated at certain intervals so that fertility is maintained at its maximum. Abad et al. (2003) indicate that the insemination interval depends on the bird's capacity to store viable sperm in the sperm nests and the number of sperm introduced into the female's reproductive tract. According to these authors, the turkey hen can store live sperm for up to 60 days, a fact that can be very similar in native turkeys, since it has been observed that once the turkey hen has been copulated by the male, she does not accept a second mating, even in rural communities where there is no tom, the female is taken to someone who has one, and a single mating is sufficient to obtain fertile eggs. According to Abad et al. (2003), fertility is maintained at good level for up to 15 days, so for maintaining fertility it will be necessary to inseminate once every two weeks.

\section{CONGLUSIONS}

The anatomical, morphological, physiological, and reproductive characteristics of the native Mexican turkey were documented. Information on this subject is scarce. Although 
it is not common to use artificial insemination in native turkeys, this technique can be adequate to conserve genetic material of animals with outstanding characteristics.

\section{REFERENGES}

Abad, M., Castelló, L.l.J.C., Carbajo, G.E., Casanovas, I.P., Dalmau, B.A., García, M.E., Leva, G.R., Martínez-Alesón, S.R. (2003). Reproducción e incubación en avicultura. Real Escuela de Avicultura, Barcelona, España.

Bakst, M.R., Akuffo, V. (2008). Turkey Sperm reside in the tubular glands in the urodeum following artificial Insemination. Poultry Science, 87,(4). 790-792. Doi: 10.3382/ps.2007-00293

Cuca, G.M., Ávila, G.E, Pró, M.A. (2009). Alimentación de las aves. Studio Lithografico. Departamento de Zootecnia. Dirección de Patronato Universitario. Universidad Autónoma Chapingo.

Cuca, G.M., Valdés, N.V.M., Gómez, V.G., \& López, P.E. (2016). Producción y manejo de aves domésticas. $1^{\mathrm{a}}$ reimp. AIP. Coatlinchán, Texcoco. Estado de México.

Illnait-Ferrer, J. (2012). Melatonina: actualidad de una hormona olvidada. Revista CENIC. Ciencias Biológicas, 43(3): 1-12.

Imai, K. (1973). Effects of avian and mammalian pituitary preparations on induction of ovulation in the domestic fowl, Gallus domesticus. Journal of Reproduction and Fertility, 33(1), 91-98. Doi: 10.1530/ jrf.0.0330091

Juárez, A. Gutiérrez, E. (2009). Control de cloequez y comportamiento productivo de guajolotas criollas. Avances en Investigación Agropecuaria, 13(1): 59-70.

Peralta, M.F. (2017). Bases de la Reproducción Aviar. Universidad Nacional de Río Cuarto FAV. Prod. Animal Producción Avícola. Argentina.

Peralta, M.F., Miazo, R. (2002). Bases de la Reproducción animal: Reproducción aviar. Universidad Nacional del Río Cuarto FAV. Disponible en: www.produccion-animal.com.ar

Ricaurte, G.S.L. (2006). Importancia de un buen manejo de la reproducción en avicultura. Revista Electrónica de Veterinaria REDVET, 7(4): 1-16.

Rodriguez, E. (2017) Cloequez. Veterinaria Digital - Avicultura, Porcicultura, Rumiantes y Acuicultura. Disponible en: https://www.veterinariadigital.com/articulos/la-cloquez/

Robinson, F.E., Renema, R. (1999). Principles of photoperiod management in female broiler breeders. University of Alberta, Department of Agricultural, Food and Nutritional Sciences. Technical news, Cobb-Vantres.

Sauveur, B., Reviers, M. (1992). Reproducción de las aves. 2a ed. Ed. Mundiprensa. Madrid, España.

Scanes, C. (1986). Pituitary gland. En P. Sturkie (Ed.), Avian Physiology (pp. 383-402). Springer Verlag. 